\title{
Effect of regular endurance exercises on management of cardiovascular health in middle-aged men
}

\author{
Bo-Ae Lee ${ }^{1,2}$, Young-Joo Kim, ${ }^{3, *}$ \\ 'Department of Anti-aging Healthcare Education, College of Education, Changwon National University, Changwon, Korea \\ ${ }^{2}$ Department of Physical Education, College of Education, Pusan National University, Busan, Korea \\ ${ }^{3}$ Department of Exercise Rehabilitation, Welfare Soojung Campus, Sungshin University, Seoul, Korea
}

This study was conducted to investigate the effect of regular endurance exercises on the management of cardiovascular health in middle-aged men. The following conclusions were drawn as the result of comparatively analyzing middle-aged men who regularly performed triathlon and cycling exercises for more than 5 years. The effect of regular endurance exercises on cardiovascular health management in middleaged men was found to be relatively positive. However, prolonged endurance exercises can cause cardiovascular disease which can adversely affect the cardiac function, and to date, no defining limit is known about the amount of exercise that improves the cardiovascular function while reducing the cardiovascular events. Therefore, aiming for exercises at moderate intensity that befit the individual's fitness level as well as conducting regular examinations to predict and manage the risk of sudden cardiac death from exercising were considered as the more effective method of cardiovascular health management.

Keywords: Middle-aged man, Triathlon, Cycling, Endurance exercise, Cardiovascular disease, Health

\section{INTRODUCTION}

Middle-aged individuals of the modern society are highly likely to be exposed to geriatric diseases, which are chronic disorders, due to their sedentary lifestyles and decrease in physical activities. In response to this, exercising has been highly recommended as a measure to prevent such diseases. In addition, regular exercise is effective for the prevention and treatment of chronic diseases such as coronary artery disease, diabetes, obesity, hypertension, cardiac failure, and depression, and reportedly extends the average lifespan of active individuals by approximately 7 years, as compared to individuals with a sedentary lifestyle (Chakravarty et al., 2008; Haskell et al., 2007).

The 2008 Physical Activity Guidelines Advisory Committee Report recommended a minimum $150 \mathrm{~min} / \mathrm{wk}$ of moderate intensity or $75 \mathrm{~min} / \mathrm{wk}$ of vigorous-intensity aerobic exercise for an adult. Excessive exercise above these recommendations that regularly engage over $20 \mathrm{hr}$ per week at an intensity of 15 metabolic equivalent of tasks (MET) induces a plethora of unique electrical, structural, and functional cardiac adaptations that are collectively termed the 'athlete's heart' (Fagard, 2003; Mann and Rosenzweig, 2012). On the other hand, while there are numerous studies which identify physical activities and exercises to be beneficial, there are also meta-analyses involving athletes engaged in chronic exercise that reported a 5-fold risk of fatal arrhythmia, like atrial fibrillation, compared with the sedentary population (Karjalainen et al., 1998), and enhanced coronary event rates (Vlachopoulos et al., 2010). In addition, it has been reported that long-term endurance exercises have the potential to adversely affect the cardiac function by inducing cardiovascular diseases, and till now, no defining limit is known about the amount of exercise that improves the cardiovascular function while reducing the cardiovascular events. Nevertheless, the popularity of athletic events and average age of participants have increased worldwide over the past 30 years, and completing in endurance events has become a personal goal for many individuals (Eijsvogels et al., 2016).
*Corresponding author: Young-Joo Kim (iD https://orcid.org/0000-0001-5937-8946 Department of Exercise Rehabilitation, Welfare Soojung Campus, Sungshin University, 2 Bomun-ro 34da-gil, Seoungbuk-gu, Seoul 02844, Korea Email: rladudwn1383@naver.com

Received: November 30, 2021 / Accepted: December 27, 2021
This is an Open Access article distributed under the terms of the Creative Commons Attribution Non-Commercial License (https://creativecommons.org/licenses/by-nc/4.0/) which permits unrestricted non-commercial use, distribution, and reproduction in any medium, provided the original work is properly cited. 
Furthermore, the main cause of sudden cardiac death among athletes under the age of 35 has been congenital heart diseases such as hypertrophic myocardiopathy; for athletes over 35 years, $70 \%$ of sudden cardiac death was induced by coronary artery diseases (Burke et al., 1992). Over the past 35 years, 135 Americans partaking triathlon died suddenly during exercise, $44 \%$ of whom died of atherosclerotic coronary artery diseases or myocardiopathy (Harris et al., 2017). As exercise-induced hypertension has been recently reported in runners, it was observed that fatal arrhythmia was closely associated with intensity and length of exercise (Kim et al., 2017). In this study, we investigated the cardiovascular effects and remodeling through graded exercise testing and echocardiography with middle-aged men who had participated in chronic excessive endurance exercise like triathlon and cycling.

\section{MATERIALS AND METHODS}

\section{Subjects}

The subjects of this study were individuals living in city Seoul, partaking in triathlon (TG, $\mathrm{n}=8)$ and cycling $(\mathrm{CG}, \mathrm{n}=8)$ exercises. The subjects had more than 5 years of experience in the exercises and were exercising 4 to 5 times a week, 1 to $2 \mathrm{hr}$ per session. In terms of the exercise intensity, the study subjects had been exercising regularly at $13-15$ on the rating of perceived exertion for each session. This study was approved by the Institutional Review Board of Pusan National University (PNU IRB/2015-31$\mathrm{HR}$ ) prior to commencement. Information on the program was provided befitting to the purpose of this study, and only the subjects who wished to participate in the experiment and provided their consent to participate in a consent form were involved in this study. The general characteristics of subjects are described in Table 1.

\section{Measurement item and method}

This study measured and analyzed the body compositions (weight, body fat percentage, body mass index), exercise stress tests (heart rate and blood pressure at rest and during exercise, electrocardiogram, cardiopulmonary fitness, myocardial ischemia, arrhythmia), and echocardiography (heart structure and function).

\section{Echocardiography}

Every subject that was prohibited from performing exercise a day before their examination, was also prohibited from consuming caffeinated drinks, alcoholic beverage, smoking, and cold medicine $12 \mathrm{hr}$ before their examination. M-mode heart ultrasound waves
Table 1. General characteristics of the subjects

\begin{tabular}{lcr}
\hline Characteristic & Triathlon group & Cycle group \\
\hline Age $(\mathrm{yr})$ & $51.50 \pm 6.04$ & $49.75 \pm 5.94$ \\
Weight $(\mathrm{kg})$ & $69.03 \pm 5.02$ & $63.63 \pm 6.22$ \\
Height $(\mathrm{cm})$ & $170.98 \pm 3.65$ & $168.32 \pm 3.20$ \\
Body mass index $\left(\mathrm{kg} / \mathrm{m}^{2}\right)$ & $23.70 \pm 1.38$ & $23.40 \pm 1.26$ \\
Body fat percentage $(\%)$ & $13.30 \pm 4.92$ & $14.76 \pm 4.42$ \\
\hline
\end{tabular}

Values are presented as mean \pm standard deviation.

were detected by the $5-\mathrm{MHz}$ transducer of the echocardiography instrument to evaluate the structure and function of the heart. The electrocardiography measurement relied on the guidelines of the American Society of Echocardiography (Sahn et al., 1978).

The measurement items were left ventricular inter dimension at end-diastole (LVIDd), left ventricular inter dimension at endsystole (LVIDs), interventricular septal thickness end-diastole (IVSd), left ventricular posterior wall thickness at end-diastole (LVPWd), left ventricular end-diastolic volume (LVEDV), left ventricular stroke volume (LVSV), left ventricular cardiac output (LVCO), left ventricular ejection fraction (LVEF), left ventricular mass (LVM), and LVM index (LVMI). LVM was calculated using the formula: $0.8 \times\left\{1.04\left[(\mathrm{LVED}+\mathrm{PWTd}+\mathrm{SWTd})^{3}-(\mathrm{LVED})^{3}\right]+0.6\right.$.

where LVED, left ventricular end diastolic diameter; PWTd, posterior wall thickness in diastole; SWTd, septum wall thickness in diastole.

The value of LVMI was obtained by dividing with body surface area. Diastolic function was determined by the tissue pulsed Doppler with $\mathrm{E}$ (E-velocity, peak mitral velocity of early filling), A (A-velocity, peak atrial velocity of atrial filling), E/A ratio, E' (E'velocity, early diastolic annulus velocity), $\mathrm{A}^{\prime}$ ( $\mathrm{A}^{\prime}$-velocity, late diastolic annulus velocity), $\mathrm{E}^{\prime} / \mathrm{A}^{\prime}$ ratio, $\mathrm{E} / \mathrm{E}^{\prime}$ ratio, and deceleration time (DT).

\section{Data processing}

The mean and standard deviation of all measured items were calculated using IBM SPSS Statistics ver. 21.0 (IBM Co., Armonk, NY, USA), and analyzed using an independent sample $t$-test to test the difference of means between groups. The statistical significance level was set as $\alpha=0.05$.

\section{RESULTS}

\section{Effects on the cardiovascular factors}

The following results were obtained from analyzing the effects of the two groups, the triathlon and cycling groups, on the cardio- 
Table 2. Between-group differences in cardiovascular factor analysis

\begin{tabular}{|c|c|c|c|c|}
\hline Variable & Group & Mean \pm SD & $t$-test & $P$-value \\
\hline RHR (beats/min) & $\begin{array}{l}\text { Triathlon } \\
\text { Cycle }\end{array}$ & $\begin{array}{l}64.12 \pm 6.28 \\
58.62 \pm 8.38\end{array}$ & -1.148 & 0.162 \\
\hline MHR (beats/min) & $\begin{array}{l}\text { Triathlon } \\
\text { Cycle }\end{array}$ & $\begin{array}{l}181.75 \pm 6.13 \\
171.37 \pm 11.79\end{array}$ & -2.207 & 0.051 \\
\hline $\mathrm{RSBP}(\mathrm{mmHg})$ & $\begin{array}{l}\text { Triathlon } \\
\text { Cycle }\end{array}$ & $\begin{array}{l}117.75 \pm 13.11 \\
125.50 \pm 7.46\end{array}$ & 1.453 & 0.174 \\
\hline $\mathrm{RDBP}(\mathrm{mmHg})$ & $\begin{array}{l}\text { Triathlon } \\
\text { Cycle }\end{array}$ & $\begin{array}{l}75.37 \pm 7.11 \\
74.00 \pm 9.62\end{array}$ & -0.325 & 0.750 \\
\hline MSBP (mmHg) & $\begin{array}{l}\text { Triathlon } \\
\text { Cycle }\end{array}$ & $\begin{array}{l}213.12 \pm 19.98 \\
223.00 \pm 20.16\end{array}$ & 0.984 & 0.342 \\
\hline $\mathrm{MDBP}(\mathrm{mmHg})$ & $\begin{array}{l}\text { Triathlon } \\
\text { Cycle }\end{array}$ & $\begin{array}{l}74.25 \pm 8.49 \\
80.87 \pm 13.14\end{array}$ & 1.197 & 0.254 \\
\hline $\mathrm{VO}_{2} \max (\mathrm{mLO} / \mathrm{kg} / \mathrm{min})$ & $\begin{array}{l}\text { Triathlon } \\
\text { Cycle }\end{array}$ & $\begin{array}{l}50.48 \pm 3.74 \\
50.14 \pm 4.93\end{array}$ & -0.155 & 0.879 \\
\hline ED (sec) & $\begin{array}{l}\text { Triathlon } \\
\text { Cycle }\end{array}$ & $\begin{array}{l}913.50 \pm 83.37 \\
859.87 \pm 110.77\end{array}$ & 1.094 & 0.294 \\
\hline
\end{tabular}

SD, standard deviation; RHR, resting heart rate; MHR, maximal heart rate; RSBP, resting systolic blood pressure; RDBP, resting diastolic blood pressure; MSBP, maximal systolic blood pressure; MDBP, maximal diastolic blood pressure; VO max, maximal oxygen uptake; $E D$, exercise duration.

Table 3. Structural analysis of intergroup differences: heart

\begin{tabular}{llrrc}
\hline Variable & Group & Mean \pm SD & t-test & $P$-value \\
\hline LVIDd $(\mathrm{cm})$ & Triathlon & $4.91 \pm 0.38$ & 0.143 & 0.888 \\
& Cycle & $4.93 \pm 0.30$ & & \\
LVIDs $(\mathrm{cm})$ & Triathlon & $3.07 \pm 0.35$ & -0.074 & 0.942 \\
& Cycle & $3.06 \pm 0.32$ & & \\
IVSd $(\mathrm{cm})$ & Triathlon & $0.97 \pm 0.07$ & -0.809 & 0.432 \\
& Cycle & $0.93 \pm 0.07$ & & \\
LVPWd $(\mathrm{cm})$ & Triathlon & $0.96 \pm 0.05$ & -1.686 & 0.123 \\
& Cycle & $0.88 \pm 0.11$ & & \\
LVEDV $(\mathrm{mL})$ & Triathlon & $116.77 \pm 26.18$ & 0.060 & 0.953 \\
& Cycle & $117.43 \pm 17.08$ & & \\
LVM $(\mathrm{g})$ & Triathlon & $173.62 \pm 22.62$ & -1.178 & 0.259 \\
& Cycle & $161.50 \pm 18.31$ & & \\
LVM index $\left(\mathrm{g} / \mathrm{m}^{2}\right)$ & Triathlon & $96.96 \pm 6.99$ & -1.289 & 0.224 \\
& Cycle & $90.12 \pm 12.73$ & & \\
\hline
\end{tabular}

SD, standard deviation; LVIDd, left ventricular inter dimension at end-diastole; LVIDs, left ventricular inter dimension at end-systole; IVSd: interventricular septal thickness end-diastole; LVPWd, left ventricular posterior wall thickness at end-diastole; LVEDV, left ventricular end-diastolic volume; LVM, left ventricular mass.

vascular factors (Table 2). No significant differences were identified between the two groups for the resting heart rate, maximal heart rate, resting systolic blood pressure, resting diastolic blood pressure, maximal systolic blood pressure, maximal diastolic blood pressure, maximal oxygen uptake, and the exercise duration. However, both groups showed exercise-induced hypertension in the maximal systolic blood pressure results.
Table 4. Result of comparison of cardiac functions

\begin{tabular}{llrcc}
\hline Variable & Group & Mean \pm SD & $t$-test & $P$-value \\
\hline LVSV (mL) & Triathlon & $77.35 \pm 19.49$ & 0.181 & 0.860 \\
& Cycle & $78.77 \pm 10.87$ & & \\
LVCO (mL/min) & Triathlon & $4.49 \pm 0.98$ & 0.417 & 0.683 \\
& Cycle & $4.68 \pm 0.78$ & & \\
LVEF (\%) & Triathlon & $66.05 \pm 6.51$ & 0.475 & 0.643 \\
& Cycle & $67.45 \pm 5.21$ & & \\
E-velocity (m/sec) & Triathlon & $0.56 \pm 0.08$ & 2.842 & $0.018^{*}$ \\
& Cycle & $0.76 \pm 0.17$ & & \\
A-velocity (m/sec) & Triathlon & $0.49 \pm 0.11$ & 2.232 & $0.043^{*}$ \\
& Cycle & $0.61 \pm 0.09$ & & \\
E/A ratio (\%) & Triathlon & $1.15 \pm 0.14$ & 0.837 & 0.423 \\
& Cycle & $1.26 \pm 0.34$ & & \\
DT (m/sec) & Triathlon & $0.23 \pm 0.03$ & -3.146 & $0.007^{* *}$ \\
& Cycle & $0.17 \pm 0.03$ & & \\
E'-velocity (m/sec) & Triathlon & $9.12 \pm 1.12$ & 1.112 & 0.295 \\
& Cycle & $10.37 \pm 2.97$ & & \\
A'-velocity (m/sec) & Triathlon & $8.12 \pm 1.35$ & 1.880 & 0.081 \\
& Cycle & $9.37 \pm 1.30$ & & \\
E'/A' ratio (\%) & Triathlon & $2.33 \pm 3.34$ & -1.008 & 0.346 \\
& Cycle & $1.13 \pm 0.34$ & & \\
E/E' ratio (\%) & Triathlon & $5.71 \pm 1.89$ & 2.238 & $0.045^{*}$ \\
& Cycle & $7.49 \pm 1.20$ & & \\
\hline
\end{tabular}

SD, standard deviation; LVSV, left ventricular stroke volume; LVCO, left ventricular cardiac output; LVEF, left ventricular ejection fraction; E-velocity, peak mitral velocity early filling; A-velocity, peak atrial velocity early filling; E/A ratio, ratio of peak mitral early and atrial filling velocities; DT, deceleration time; $E^{\prime}$-velocity, early diastolic annulus velocity; $A^{\prime}$-velocity, late diastolic annulus velocity; $E^{\prime} / A^{\prime}$ ratio, ratio of early diastolic annulus velocity and late diastolic annulus velocity; $E / E$ ' ratio, ratio of peak mitral early and early diastolic annulus velocity.

${ }^{*} P<0.05$. ${ }^{* *} P<0.01$.

\section{Effects on the heart structure}

The following results were obtained on analyzing the effects of the two groups, the triathlon and cycling groups, on the heart structure (Table 3). Similar to the cardiovascular factors, no significant differences were identified between the two groups for the heart structure in the LVIDd, LVIDs, IVSd, LVPWd, LVEDV, LVM, or LVMI.

\section{Differences in the heart function}

The following results were obtained from analyzing the effects of the two groups, the triathlon and cycling groups, on the cardiac function (Table 4). No differences were found between the two groups for the cardiac function in the LVSV, LVCO, LVEF, E-velocity (peak mitral velocity early filling), A-velocity (peak atrial velocity early filling), E/A ratio (ratio of peak mitral early and atrial filling velocities), or $\mathrm{E}^{\prime} / \mathrm{A}^{\prime}$ ratio (ratio of early diastolic annulus velocity and late diastolic annulus velocity). However, there were 
significant differences in the early diastolic annulus velocity $(P<$ $0.05)$, late diastolic annulus velocity $(P<0.05)$, DT $(P<0.01)$, and the ratio of the peak mitral early and early diastolic annulus velocity $(P<0.05)$.

\section{DISCUSSION}

In this study, exercise stress tests and echocardiography were conducted on the subjects who regularly participated in triathlon and cycling exercises, and the cardiovascular factors, heart structures, and cardiac functions were analyzed for each group. Cardiac injuries associated with sports have been discussed extensively (Leischik and Spelsberg, 2014; Oxborough et al., 2010), exercises have been observed to be particularly improving the functional status of patients with cardiac conditions in addition to providing prevention and treatment of cardiovascular diseases, and reducing the risk factors (Flynn et al., 2009; Lawler et al., 2011). However, sudden death is the leading exercise-related cardiac injury with most athletes under the age of 35 dying from coronary artery disease (Wike and Kernan, 2005), while the other general causes include hypertrophic cardiomyopathy, coronary disease, coronary anomalies, myocarditis, and arrhythmogenic right ventricle (Marijon et al., 2011; Solberg et al., 2010). Not all of the differences in the cardiovascular factors were found to be significant in this study, but both groups showed exercise-induced hypertension for the maximal systolic blood pressure.

Exercise-induced hypertension refers to systolic blood pressure and diastolic blood pressure being less than $140 / 90 \mathrm{mmHg}$ at rest, and the systolic blood pressure reaching $210 \mathrm{mmHg}$ or above at maximal exercise (Singh et al., 1999). One study reported individuals with exercise-induced hypertension to be five to ten times more likely to develop hypertension in the future (Singh et al., 1999), and exercise-induced hypertension as an independent risk factor for cardiovascular diseases (Tzemos et al., 2015). The mechanism of exercise-induced hypertension is known to be caused by the blood pressure which excessively elevates with increased exercise intensity, as the peripheral vascular resistance increases from vasodilation disorder that is caused by the dysfunction of vascular endothelial cells (Stewart et al., 2004; Wilson et al., 1990). Other studies on exercise-induced hypertension reported that it could cause eccentric remodeling of the cardiac structures in people who performed prolonged endurance training (Hoogsteen et al., 2004), as well as other remodeling processes alike (Karlstedt et al., 2012; La Gerche et al., 2012; Leischik et al., 2014). Participants of triathlon exercises may develop a temporary overload (Oomah et al.,
2011), and it was also reported that the inner diameter of the left ventricle and the thickness and mass of the middle and posterior ventricular walls increased from exercising, due to the increase in the arterial pressure (Gerche et al., 2011; Leischik and Spelsberg, 2014), which are also consistent with the results of this study.

These results indicate the consequences of chronic vascular pressure caused by high exercise intensity over a prolonged period which suggest that such results may be caused by the stress that accelerates the fibrosis of various myocardium conditions (Heidbuchel et al., 2011; Vlachopoulos et al., 2010). Furthermore, the increase in the left ventricle also showed an elevation in the enddiastolic left ventricular volume, LVM, and LVMI. However, ventricular hypertrophy and high LVM identified in this study were not pathological conditions such as congenital hypertrophic cardiomyopathy, which can cause sudden death in young athletes (Maron et al., 2009), and there were no statistically significant differences in the heart structure between the two groups. On the other hand, the term 'athlete's heart' (George et al., 1991) has been used since 1899 as endurance training-type exercises such as triathlon and cycling were known to physiologically induce cardiovascular adaptation and systematic changes in the cardiac structure (Utomi et al., 2014) and produce beneficial changes (McMullen et al., 2007). However, continuous follow-up investigations are needed as it was reported that structural changes in the left ventricle were associated with an increased risk of cardiovascular morbidity and mortality (Kim et al., 2020).

In terms of heart functions, the heart rate of 60 beats per minute and the diastolic blood pressure close to the state of bradycardia at rest, which are generally found in hemodynamic responses from the effect of long-term exercise, corresponded with the results of this study. Upon examining the previous studies, this phenomenon appears to have been caused by the high stroke volume and increased vagal tone from exercise adaptation (Sugiura et al., 2015). Moreover, those who performed exercises over a long period were found to have increased cardiac output of up to $40 \mathrm{~L}$ (Pluim et al., 2000), which might be the result of maintaining cardiac output as a compensatory mechanism for the increase in the stroke volume. However, no statistically significant effects were found in this study despite the increase in the figures, which suggests that regular and long-term performance of any type of exercise can improve the heart function.

The LVEF, an index representing the contractility of the left ventricle, is evaluated by the ratio of the total blood volume entering the left ventricle and the remaining blood volume after one ejection. A study which investigated the LVEF between exercising and 
nonexercising groups, as well as the differences between endurance and strength athletes, showed no significant differences between the groups (Vinereanu et al., 2002), which were also consistent with the results of this study. As the pressure in the left atrium becomes higher than that of the left ventricle, the mitral valve opens and blood flows in rapidly, which is referred to as the mitral velocity early filling stage. When the left atrium contracts, the remaining left atrial blood flows into the left ventricle, which is referred to as the peak atrial velocity early filling stage (Hurrell et al., 1997). The figures were slightly higher or lower in this study, but all the figures were within the normal ranges and were found to have a statistically significant effect.

The reason for this is that the DT and early diastolic annulus velocity were lower in the aerobic and anaerobic exercise groups as well as the triathlon athletes in comparison to the general population (Naylor et al., 2005), and the ratio of peak mitral and atrial early filling velocities have also been reported as high (Douglas et al., 1986), which was also consistent with the results of this study. In addition, athletes participating in the endurance exercises were reported to have slightly higher early diastolic annulus velocities and late diastolic annulus velocities (Vinereanu et al., 2002), but no statistically significant differences were found in the ratio of early diastolic annulus velocities and late diastolic annulus velocities (Caselli et al., 2015), which were also consistent with the results of this study. Moreover, the ratio of peak mitral early and early diastolic annulus velocity, which was considered as the normal when less than eight, and abnormal when greater than 15 , was found to have a statistically significant effect on the two groups. However, one study reported the ratio of peak mitral early and early diastolic annulus velocity to be unaffected by exercise (Caselli et al., 2015). Therefore, this is considered to hold no clinical significance as the results from this study were within the normal ranges. To summarize the abovementioned results, regular endurance exercises were found to have a relatively positive effect on the management of cardiovascular health in middle-aged men.

However, studies on prolonged exercise and lifelong endurance athletes suggest that prolonged exercise training may create scarring, fibrosis, and myocardial injury even in individuals without a genetic predisposition to cardiomyopathy (Gerche et al., 2012). Therefore, aiming for exercises at a safe moderate intensity that befit the individual's fitness level and conducting regular examinations to predict and manage the risk of sudden cardiac death from exercising were considered as the more effective methods of cardiovascular health management.

\section{CONFLICT OF INTEREST}

No potential conflict of interest relevant to this article was reported.

\section{ACKNOWLEDGMENTS}

The authors received no financial support for this article.

\section{REFERENCES}

Burke AP, Farb A, Virmani R. Causes of sudden death in athletes. Cardiol Clin 1992;10:303-317.

Caselli S, Di Paolo FM, Pisicchio C, Pandian NG, Pelliccia A. Patterns of left ventricular diastolic function in Olympic athletes. J Am Soc Echocardiogr 2015;28:236-244.

Chakravarty EF, Hubert HB, Lingala VB, Fries JF. Reduced disability and mortality among aging runners: a 21-year longitudinal study. Arch Intern Med 2008;168:1638-1646.

Douglas PS, O'Toole ML, Hiller WD, Reichek N. Left ventricular structure and function by echocardiography in ultraendurance athletes. Am J Cardiol 1986;58:805-809.

Eijsvogels TM, Fernandez AB, Thompson PD. Are there deleterious cardiac effects of acute and chronic endurance exercise? Physiol Rev 2016; 96:99-125.

Fagard R. Athlete's heart. Heart 2003;89:1455-1461.

Flynn KE, Piña IL, Whellan DJ, Lin L, Blumenthal JA, Ellis SJ, Fine LJ, Howlett JG, Keteyian SJ, Kitzman DW, Kraus WE, Miller NH, Schulman KA, Spertus JA, O'Connor CM, Weinfurt KP. Effects of exercise training on health status in patients with chronic heart failure: hf-action randomized controlled trial. JAMA 2009;301:1451-1459.

George KP, Wolfe LA, Burggraf GW. The 'athletic heart syndrome'. A critical review. Sports Med 1991;11:300-330.

Gerche AL, Burns AT, Mooney DJ, Inder WJ, Taylor AJ, Bogaert J, Macisaac AI, Heidbüchel H, Prior DL. Exercise-induced right ventricular dysfunction and structural remodelling in endurance athletes. Eur Heart J 2012;33:998-1006.

Gerche AL, Heidbüchel H, Burns AT, Mooney DJ, Taylor AJ, Pfluger HB, Inder WJ, Macisaac AI, Prior DL. Disproportionate exercise load and remodeling of the athlete's right ventricle. Med Sci Sports Exerc 2011; 3:974-981.

Harris KM, Creswell LL, Haas TS, Thomas T, Tung M, Isaacson E, Garberich RF, Maron BJ. Death and cardiac arrest in U.S. triathlon participants, 1985 to 2016: a case series. Ann Intern Med 2017;167:529-535.

Haskell WL, Lee IM, Pate RR, Powell KE, Blair SN, Franklin BA, Macera 
CA, Heath GW, Thompson PD, Bauman A. Physical activity and public health: updated recommendation for adults from the American College of Sports Medicine and the American Heart Association. Circulation 2007;116:1081-1093.

Heidbuchel H, Prior DL, La Gerche A. Ventricular arrhythmias associated with long-term endurance sports: what is the evidence? Br J Sports Med 2011;110:1622-1626.

Hoogsteen J, Bennekers JH, van der Wall EE, van Hemel NM, Wilde AA, Crijns HJ, Gorgels AP, Smeets JL, Hauer RN, Jordaens JL, Schalij MJ. Recommendations and cardiological evaluation of athletes with arrhythmias. Neth Heart J 2004;12:157-164.

Hurrell DG, Nishimura RA, Ilstrup DM, Appleton CP. Utility of preload alteration in assessment of left ventricular filling pressure by doppler echocardiography: a simultaneous catheterization and doppler echocardiographic study. J Am Coll Cardiol 1997;30:459-467.

Karjalainen J, Kujala UM, Kaprio J, Sarna S, Viitasalo M. Lone atrial fibrillation in vigorously exercising middle aged men: case-control study. BMJ 1998;13;316:1784-1785.

Karlstedt E, Chelvanathan A, Da Silva M, Cleverley K, Kumar K, Bhullar N, Lytwyn M, Bohonis S, Oomah S, Nepomuceno R. The impact of repeated marathon running on cardiovascular function in the aging population. J Cardiovasc Magn Reson 2012;14:58.

Kim HJ, Jeong MH, Yoon HJ, Kim YC, Sohn SJ, Kim MC, Sim DS, Hong YJ, Kim JH, Youngkeun Ahn YK, Cho JY, Kim KH, Park JC. Difference of clinical outcomes according to left ventricular hypertrophy and its subtype in Korean patients with acute myocardial infarction. Korean J Med 2020;95:387-397.

Kim YJ, Park YB, Kang DH, Kim CH. Excessive exercise habits in marathoners as novel indicators of masked hypertension. Biomed Res Int 2017;2017:1342842.

La Gerche A, Burns AT, Mooney DJ, Inder WJ, Taylor AJ, Bogaert J, MacIsaac AI, Heidbüchel H, Prior DL. Exercise-induced right ventricular dysfunction and structural remodelling in endurance athletes. Eur Heart J 2012;33:998-1006.

Lawler PR, Filion KB, Eisenberg MJ. Efficacy of exercise-based cardiac rehabilitation post-myocardial infarction: a systematic review and meta-analysis of randomized controlled trials. Am Heart J 2011;162:571584.

Leischik R, Spelsberg N. Endurance sport and "cardiac injury": a prospective study of recreational ironman athletes. Int J Environ Res Public Health 2014;11:9082-9100.

Leischik R, Spelsberg N, Niggemann H, Dworrak B, Tiroch K. Exerciseinduced arterial hypertension - an independent factor for hypertrophy and a ticking clock for cardiac fatigue or atrial fibrillation in athletes? F1000Res 2014;3:105.
Mann N, Rosenzweig A. Basic science for clinicians: can exercise teach us how to treat heart disease? Circulation 2012;126:2625-35.

Marijon E, Tafflet M, Celermajer DS, Dumas F, Perier MC, Mustafic H, Toussaint JF, Desnos M, Rieu M, Benameur N. Sports-related sudden death in the general population. Circulation 2011;124:672-681.

Maron BJ, Doerer JJ, Haas TS, Tierney DM, Mueller FO. Sudden deaths in young competitive athletes: analysis of 1866 deaths in the United States, 1980-2006. Circulation 2009;119:1085-1092.

McMullen JR, Amirahmadi F, Woodcock EA, Schinke-Braun M, Bouwman RD, Hewitt KA, Mollica JP, Zhang L, Zhang Y, Shioi T, Buerger A, Izumo S, Jay PY, Jennings GL. Protective effects of exercise and phosphoinositide 3-kinase(p110 $\alpha)$ signaling in dilated and hypertrophic cardiomyopathy. Proc Natl Acad Sci U S A 2007;104:612-617.

Naylor LH, Arnolda LF, Deague JA, Playford D, Maurogiovnni A, ÓDriscoll $G$. Reduced ventricular flow propagation velocity in elite athletes is augmented with the resumption of exercise training. J Physiol 2005; 563:957-963.

Oomah SR, Mousavi N, Bhullar N, Kumar K, Walker JR, Lytwyn M, Colish J, Wassef A, Kirkpatrick ID, Sharma S, Jassal DS. The role of threedimensional echocardiography in the assessment of right ventricular dysfunction after a half marathon: comparison with cardiac magnetic resonance imaging. J Am Soc Echocardiogr 2011;24:207-213.

Oxborough D, Birch K, Shave R, George K. "Exercise-induced cardiac fatigue" $^{\prime \prime}$-a review of the echocardiographic literature. Echocardiography 2010;27:1130-1140.

Pluim BM, Zwinderman AH, van der Laarse A, van der Wall EE. The athlete's heart. a meta-analysis of cardiac structure and function. Circulation 2000;101:336-344.

Sahn D, Edmaria A, Kisslo J, Weyman A. Recommandations regarding quantitation in m-mode echocardiography: results of a survey of echocardiographic measurements. Circulation 1978;58:1072-1083.

Singh JP, Larson MG, Manolio TA, O’Donnell CJ, Lauer M, Evans JC, Levy D. Blood pressure response during treadmill testing as a risk factor for new-onset hypertension. The Framingham heart study. Circulation 1999;99:1831-1836.

Solberg EE, Gjertsen F, Haugstad E, Kolsrud L. Sudden death in sports among young adults in Norway. Eur J Cardiovasc Prev Rehabil 2010; 17:337-341.

Stewart KJ, Sung J, Silber HA, Fleg JL, Kelemen MD, Turner KL, Bacher AC, Dobrosielski DA, DeRegis JR, Shapiro EP, Ouyang P. Exaggerated exercise blood pressure is related to impaired endothelial vasodilator function. Am J Hypertension 2004;17:314-320.

Sugiura Kojima M, Noda A, Miyata S, Kojima J, Hara Y, Minoshima M, Murohara T. The effect of habitual physical training on left ventricular function during exercise assessed by three-dimensional echocardiog- 
raphy. Echocardiography 2015;32:1670-1675.

Tzemos N, Lim PO, Mackenzie IS, Macdonald TM. Exaggerated exercise blood pressure response and future cardiovascular disease. J Clin Hypertens 2015;17:837-844.

Utomi V, Oxborough D, Ashley E, Lord R, Fletcher S, Stembridge M, Shave R, Hoffman MD, Whyte G, Somauroo J, Sharma S, George K. Predominance of normal left ventricular geometry in the male 'athlete's heart'. Heart 2014;100:1264-1271.

Vinereanu D, Florescu N, Sculthorpe N, Tweddel AC, Stephens MR, Fraser AG. Left ventricular long-axis diastolic function is augmented in the hearts of endurance-trained compared with strength-trained athletes. Clin Sci (Lond) 2002;103:249-257.

Vlachopoulos C, Kardara D, Anastasakis A, Baou K, Terentes-Printzios D, Tousoulis D, Stefanadis C. Arterial stiffness and wave reflections in marathon runners. Am J Hypertens 2010;23:974-979.

Wike J, Kernan M. Sudden cardiac death in the active adult: causes, screening, and preventive strategies. Curr Sports Med Rep 2005;4:76-82.

Wilson MF, Sung BH, Pincomb GA, Lovallo WR. Exaggerated pressure response to exercise in men at risk for systemic hypertension. Am J Cardiol 1990;66:731-736. 